\title{
The Impact of Forest Conversion to the Avifaunal Diversity in Northern Flank of Knuckles Mountain Forest Range
}

\author{
Subasinghe K.* and Weerawardhena S.R.
}

\author{
Department of Zoology, Faulty of Science, University of Kelaniya, Kelaniya, Sri Lanka \\ *kalya_subasinghe@yahoo.com
}

\begin{abstract}
Most of the natural forests throughout the world have been converted to human land-uses in recent decades. Such conversions have affected the forest biodiversity at different levels. Knuckles mountain forest range (KMFR) in Sri Lanka that has been designated as a world heritage site for its high level of biodiversity is heavily disturbed and fragmented due to various human activities mainly tea and cardamom plantation. In the present study the bird species richness, abundance and similarity of bird species composition were investigated in three prominent agricultural land-uses i.e. Pinus, cardamom and abandoned tea plantations, and in an undisturbed sub-montane forest in Northern Flank of KMFR. Also vegetation structure of each land-use type was studied to assess the significance of vegetation structural components (tree density, tree height, canopy cover, vertical stratification, herbaceous cover) to the avifaunal diversity.
\end{abstract}

Bird sampling was carried out between March and September, 2012 using the fixed radius point count method. Each land-use type had 28 point count stations that were sampled by means of 10 minutes recording session. Point counts were taken between 6.00 to 9.30 am and 3.30 to $5.00 \mathrm{pm}$. A total of 1,023 individuals belonging to 51 bird species were observed during the study. The Pinus and abandoned tea plantations supported a fewer number of bird species than undisturbed forest (One-way ANOVA; $\mathrm{p}<0.05$ ), but the cardamom plantation with diverse, native shade trees, had a bird species richness comparable to undisturbed forest (One-way ANOVA; p>0.05). Relative abundance of birds in undisturbed forest was significantly higher than in abandoned tea plantation, but was significantly lower than in cardamom plantation (One-way ANOVA; $\mathrm{p}<0.05$ ). Jaccard index $(\mathrm{Cj})$ has shown that avifaunal species composition had higher similarity between undisturbed site and cardamom plantation site $(\mathrm{Cj}=0.56)$, compared to abandoned tea plantation $(\mathrm{Cj}=0.28)$ and Pinus plantation $(\mathrm{Cj}=0.19)$.

Of the vegetation variables considered, canopy cover and the vertical stratification has a strong positive linear effect on the bird species richness (canopy cover; $r=0.738$, vertical stratification; $r=0.813$ ). It can be concluded that although the conversion of forests could significantly affect the avifaunal diversity and its composition, cardamom plantations could play an important role in the conservation of bird species. However, further studies are needed to understand its long-term potential to sustain similar bird composition and richness.

Keywords: Forest conversion, Land-use types, Bird species richness, Vegetation structure, Knuckles Mountain Forest Range 